University of Nebraska - Lincoln

DigitalCommons@University of Nebraska - Lincoln

Faculty Publications: Department of Entomology

October 1997

\title{
Use of Rubidium to Label Lysiphlebus testaceipes (Hymenoptera: Braconidae), a Parasitoid of Greenbugs (Homoptera: Aphididae), for Dispersal Studies
}

\author{
Odair A. Fernandes \\ University of Nebraska-Lincoln, oafernandes@fcav.unesp.br \\ Robert J. Wright \\ University of Nebraska-Lincoln, rwright2@unl.edu \\ Karl H. Baumgarten \\ University of Nebraska-Lincoln, kbaumgarten1@unl.edu \\ Z. B. Mayo \\ Univesity of Nebraska - Lincoln, zmayo1@unl.edu
}

Follow this and additional works at: https://digitalcommons.unl.edu/entomologyfacpub

Part of the Entomology Commons

Fernandes, Odair A.; Wright, Robert J.; Baumgarten, Karl H.; and Mayo, Z. B., "Use of Rubidium to Label Lysiphlebus testaceipes (Hymenoptera: Braconidae), a Parasitoid of Greenbugs (Homoptera: Aphididae), for Dispersal Studies" (1997). Faculty Publications: Department of Entomology. 107.

https://digitalcommons.unl.edu/entomologyfacpub/107

This Article is brought to you for free and open access by the Entomology, Department of at DigitalCommons@University of Nebraska - Lincoln. It has been accepted for inclusion in Faculty Publications: Department of Entomology by an authorized administrator of DigitalCommons@University of Nebraska - Lincoln. 


\title{
Use of Rubidium to Label Lysiphlebus testaceipes (Hymenoptera: Braconidae), a Parasitoid of Greenbugs (Homoptera: Aphididae), for Dispersal Studies
}

\author{
ODAIR A. FERNANDES, ${ }^{1}$ ROBERT J. WRIGHT, ${ }^{2}$ KARL H. BAUMGARTEN, ${ }^{3}$ AND Z B MAYO
}

Department of Entomology, University of Nebraska-Lincoln, Lincoln, NE 68583-0816

\begin{abstract}
Environ. Entomol. 26(5): 1167-1172 (1997)
ABSTRACT A reliable method of labeling is needed to study dispersal of the braconid parasitoid, Lysiphlebus testaceipes (Cresson), an important biological control of greenbugs, Schizaphis graminum (Rondani), on grain sorghum, Sorghum bicolor (L.) Moench. The feasibility of using aqueous solutions of rubidium chloride $(\mathrm{RbCl})$ applied as a foliar spray or soil drench to label greenbugs and $L$. testaceipes developing within greenbugs was studied. Laboratory and field studies were conducted to identify the minimal concentration of $\mathrm{RbCl}$ to assure labeling of greenbugs and wasps, persistence of $\mathbf{R b}$ throughout the wasp's life span, mobility of $\mathbf{R b}$ to unsprayed sorghum leaves, and feasibility of studying dispersal using a release-recapture technique with Rb-labeled wasps. Both greenbugs and wasps could be labeled using $\mathrm{RbCl}$ at concentrations of 2,500-10,000 ppm. Rubidium content in labeled wasps did not significantly vary during the first $7 \mathrm{~d}$ after emergence. Greenbugs feeding on unsprayed leaves were labeled up to $4 \mathrm{wk}$ after leaves were sprayed. Rb-labeled wasps were found at the maximum trap distance from the release site $(60 \mathrm{~m})$ within $1 \mathrm{~d}$ after release.
\end{abstract}

KEY WORDS Lysiphlebus testaceipes, greenbugs, parasitoids, dispersal, rubidium chloride, grain sorghum

DESPITE THE IMPORTANCE of parasitoids for biological control of pests, studies of their dispersal are rare. Release-recapture techniques often have been used for insect dispersal studies (Southwood 1978). According to Akey (1991), markers should be easy to apply, require minimal manipulation, be easily recognized, persist with certainty, and be without deleterious biological effects to the recipient.

The use of trace elements such as rubidium $(\mathrm{Rb})$, cesium (Cs), and strontium ( $\mathrm{Sr}$ ) has been one of the best approaches to label insects (Hopper 1991, Stimmann 1991). Elevated levels of trace elements allows discrimination of wild and labeled individuals. The concentration of a trace element has been increased in insects by incorporating it into artificial diets or by spraying their host plants. $\mathrm{Rb}$ was first proposed as an internal physiological marker by Berry et al. (1972). These authors emphasized that $\mathrm{Rb}$ is an excellent marker because it is rare in nature and does not pose an environmental hazard (nonradioactive properties). This element also is easily absorbed by plants, which makes its use simple. $\mathrm{Rb}$ and other trace elements have been used to label

\footnotetext{
${ }^{1}$ Current address: Department of Entomology and Nematology, FCAVJ/UNESP, 14870-000, Jaboticabal SP, Brazil.

${ }^{2}$ To whom reprint requests should be sent. Mailing address: South Central Research \& Extension Center, Box 66, Clay Center, NE 68933.

${ }^{3}$ Department of Geology, University of Nebraska, Lincoln, NE 68583-0340.
}

herbivores, predators, and parasitoids (Frazer and Raworth 1974, Fleischer et al. 1986, Jackson and Debolt 1990, Jackson 1991). To label parasitoids, transferral of $\mathrm{Rb}$ from lower trophic levels is usually required because few parasitoids can be reared on artificial diets (Jackson 1991). Rb is eliminated from labeled insects by excretion, oviposition, and mating (Van Steenwyk 1991). The rate of excretion depends upon the insect's feeding habits and the stage in which $\mathbf{R b}$ was acquired.

In addition to benefits such as ease of application under field conditions (Graham et al. 1978) and detection by techniques such as atomic absorption spectrophotometry and atomic emission spectrophotometry (Hopper 1991), Rb does not adversely affect the biology and behavior of insects under moderate concentrations (Stimmann et al. 1973, Graham and Wolfenbarger 1977). Larvae of pink bollworm, Pectinophora gossypiella (Saunders), fed on RbCl-supplemented artificial diet were not affected by concentrations of $\leq 85,500 \mathrm{ppm}$, beyond which high larval mortality was noticed (Van Steenwyk et al. 1978).

Several sorghum, Sorghum bicolor (L.) Moench, insects-Helicoverpa zea (Boddie), Spodoptera frugiperda (J. E. Smith), Epitrix spp., Diabrotica spp., Cicadellidae, Aphididae, Coccinelidae, Chrysopidae, and Syrphidae representing both herbivores and predators- have been labeled by spraying $\mathrm{Rb}$ on plants (Graham et al. 1978). Insects collected 
from treated plants showed higher amounts of $\mathrm{Rb}$ $28 \mathrm{~d}$ after plants were sprayed. There is no reference in that study regarding effects on parasitoids.

Dispersal studies can be conducted by using labeled insects which are released, recaptured, and identified. According to Hayes (1991), traps distributed along concentric circles around the release site and frequent sampling are the best approach for dispersal studies of insects when dispersal behavior is not well known. Limited previous research indicated that $L$. testaceipes did not disperse more than a few meters from the release site (Starks et al. 1973).

Labeling of Lysiphlebus testaceipes (Cresson), an important parasitoid of greenbugs, Schizaphis graminum (Rondani), in Nebraska, is essential if its dispersal is to be studied. Thus, the ability to apply and detect $\mathbf{R b}$ accurately in parasitoids must be evaluated and analyzed on an individual insect basis to allow separation of labeled and unlabeled parasitoids. The objectives of this study were as follows: (1) to determine if $\mathrm{Rb}$ could be detected in both greenbugs, and its parasitoid, $L$. testaceipes, after application to plants; (2) to determine the mobility of $\mathrm{Rb}$ in sorghum plants; and (3) to test the feasibility of using a release-recapture method to measure dispersal of $\mathbf{R b}$-labeled $L$. testaceipes under field conditions.

\section{Materials and Methods}

$\mathrm{Rb}$ Detection in Greenbugs and Parasitoids. Seeds of a biotype-E greenbug susceptible sorghum hybrid (Funk 522 DR) were sown in 200-ml plastic pots filled with a mixture of soil, sand, and vermiculite $(\approx 10: 2.5: 1)$. After emergence, plants were thinned to 1 per pot. These plants were maintained in a greenhouse for $4 \mathrm{wk}$, after which they were transferred to the laboratory (room temperature). Plants were watered once a week.

The sorghum seedlings ( $4 \mathrm{wk}$ old) were treated with solutions of $\mathrm{RbCl}-$ either $0 ; 500 ; 1,000 ; 2,500$; 5,000 ; or $10,000 \mathrm{ppm}$ of $\mathrm{RbCl}$ sprayed on plants or $10,000 \mathrm{ppm}$ of $\mathrm{RbCl}$ applied as a soil drench. The experimental design was completely randomized with 5 replications (plants). The spray solutions were prepared with distilled water, $\mathrm{RbCl}$ (Sigma, St. Louis, MO), and $0.5 \mathrm{ml}$ of a wetting agent (Activator 90; Loveland Industries, Loveland, CO). These solutions were applied to plants using a 1-liter garden sprayer. The treatment with 10,000 -ppm soil drench was prepared as was the spray solutions but without the wetting agent. The control treatment was prepared with all ingredients except $\mathrm{RbCl}$. Plants were sprayed thoroughly to runoff and allowed to dry for $24 \mathrm{~h}$. About $20 \mathrm{ml}$ of solution per plant was used for both treatment methods.

Thirty parasitoids (sex ratio 1:1) were placed in a cage with $\approx 100$ laboratory-reared biotype E greenbugs for $24 \mathrm{~h}$. Plants were then infested with 5 greenbugs that had been exposed to parasitoids for $24 \mathrm{~h}$. Aphids were transferred to plants using a camel's-hair brush. Plants were caged and maintained at room temperature. After $\approx 5 \mathrm{~d}$, parasitized aphids became mummies. Each mummy was carefully removed from the plants and isolated in gelatine capsules (Eli Lilly, Indianapolis, IN) to allow individual parasitoids to emerge. Emergence occurred after 3-4 d. Adults were immediately transferred to a freezer $\left(-10^{\circ} \mathrm{C}\right)$ for a few minutes and then transferred to clean microcentrifuge tubes (Fisher Scientific, Pittsburgh, PA). These tubes were kept in the freezer at $-10^{\circ} \mathrm{C}$ for later analysis of $\mathrm{Rb}$ content. Some unparasitized greenbugs were also kept in the freezer for analysis.

Rubidium Analysis. Insects were individually placed in 5-ml acid-washed Teflon bombs. To each bomb, $0.5 \mathrm{ml}$ of trace element grade hydrochloric acid and $0.5 \mathrm{ml}$ of trace element grade nitric acid was added. Bombs were sealed and heated at $80^{\circ} \mathrm{C}$ for $24 \mathrm{~h}$. Bombs were cooled, and the digested sample solutions were transferred to acid-washed $25-\mathrm{ml}$ volumetric flasks. Indium was added to the sample solutions as an internal standard and the flasks were brought up to volume with ultra-pure $(18 \mathrm{M} \mathrm{ohm} /$ $\mathrm{cm}$ ) water. This resulted in an insect solution concentration of 1-4 ppm insect (depending on insect weight) with a 50-ppb indium internal standard spike. Because individual insects had too little mass for accurate dry-weight measurement, insect weight was estimated by weighing a large number of insects and calculating an average dry weight for aphids $(0.13 \mathrm{mg})$ and wasps $(0.026 \mathrm{mg})$. Rubidiumstandard solutions of 1,10 , and $100 \mathrm{ppb}$ were prepared using trace element grade rubidium chloride and ultra-pure water. Rubidium content of each solution was analyzed using ICP Spectroscopy (VG Plasmaquad ICP-MS, Danvers, MA). Five scans of each standard solution and 3 scans of each sample solution were done using an aliquot of $\approx 1 \mathrm{ml}$ per scan. Rubidium content of each sample was calculated by averaging the results of the 3 sample scans. Rubidium content of each insect was calculated from the insect solution concentration.

Insects were considered labeled if they exceeded at least 3 standard deviations from the mean background level of insects feeding on untreated plants (Stimmann 1974). Dose-response curves for both greenbugs and parasitoids were described by polynomial regression analysis (SAS Institute 1990).

Rb Detection Throughout Parasitoid's Life Span. Sorghum seedlings and parasitized greenbugs were obtained as described above, but parasitoids had been reared in greenbugs on field-caged sorghum for a few generations before use in this study. A solution of $5,000 \mathrm{ppm} \mathrm{RbCl}$ was prepared and sprayed on all plants. Plants were covered with plastic tube cages (Morgan et al. 1980) in the laboratory and held at room temperature. Plants were infested with 5 unparasitized greenbugs per plant $24 \mathrm{~h}$ after spraying. Approximately $1 \mathrm{wk}$ after greenbug infestation, newly emerged parasitoids were placed in the cages. A randomized complete block design with 4 replications was used. Blocks con- 
sisted of different parasitoid introduction dates because of irregular parasitoid emergence. Only 1 parasitoid was kept per cage in 3 replications. A 4th block was conducted with parasitoid pairs ( 1 male and 1 female) rather than with individuals in the cage. Parasitoids were removed from cages and frozen at $-10^{\circ} \mathrm{C}$ on $1,2,3,4,5,6$, and $7 \mathrm{~d}$ after emergence. Sample preparation and $\mathrm{Rb}$ analysis were performed similarly to the previous experiment. Analysis of variance (ANOVA) for a randomized complete block design was conducted (SAS Institute 1990) to test whether rubidium content varied significantly with time after wasp emergence.

Rb Mobility in Sorghum Plants. Sorghum plants were maintained similarly to the 1st experiment, but $700-\mathrm{ml}$ clay pots were used instead of plastic pots. Seedlings were thinned to 1 plant per pot. Pots were transferred to the laboratory when plants had 3 fully developed leaves. Pots were watered twice a week. Half of the plants were randomly selected and sprayed with $5,000 \mathrm{ppm} \mathrm{RbCl}$ solution to runoff as described previously. The check consisted of plants sprayed with the same solution without $\mathrm{RbCl}$. Seven replications were used. Plants were infested with greenbugs $25 \mathrm{~d}$ after treatments, after new unsprayed leaves had emerged. Each plant was infested with 2 adult greenbugs, 1 on the 3 rd leaf (previously treated) and the other on the 6th leaf (emerged after treatment). Aphids were caged on these leaves using a small 1 -sided leaf cage made from adhesive foam mounting (Lundell Manufacturing, Minneapolis, MN) with an opening ( $5 \mathrm{~mm}$ diameter) covered with muslin. Aphids were removed $1 \mathrm{wk}$ later and transferred to clean plastic microcentrifuge tubes and held at $-10^{\circ} \mathrm{C}$. The leaves on which the aphids were caged were removed, dried for $30 \mathrm{~d}$ at room temperature, weighed, and transferred to clean plastic microcentrifuge tubes. Greenbug and leaf $\mathbf{R b}$ content were analyzed as described above, but they were digested in a solution of $1.0 \mathrm{ml}$ trace element grade hydrochloric acid and $1.0 \mathrm{ml}$ trace element grade nitric acid for $24 \mathrm{~h}$. ANOVA was conducted with leaves as subplots and $\mathrm{Rb}$ treatments as main plots in a split plot design (SAS Institute 1990).

Release-Recapture Study. A 2-ha sorghum field located near Mead (Saunders County), NE, $48 \mathrm{~km}$ $\mathrm{N}$ of Lincoln, NE, was used. Sorghum (Dekalb 42Y) plants were in stage 5 (boot stage) (Vanderlip 1972). One $8-\mathrm{m}^{3}$ saran fabric (32 by 32 mesh) cage (Bioquip Products, Gardena, CA) was placed in the center of the study area. Sorghum plants in the cage were artificially infested with large numbers of greenbugs. Two weeks later, plants were sprayed with a 5,000-ppm $\mathrm{RbCl}$ solution prepared in the same way as the laboratory experiments. Plants were throughly sprayed to runoff using a hand sprayer. Parasitoids ( $\approx 150$ adults) were released in the cage immediately after spraying. Eleven days after parasitoid release, 350 aphid mummies were observed. Before removal of the cage, 81 white sticky Pherocon 1C trap liners (Trécé, Salinas, CA)

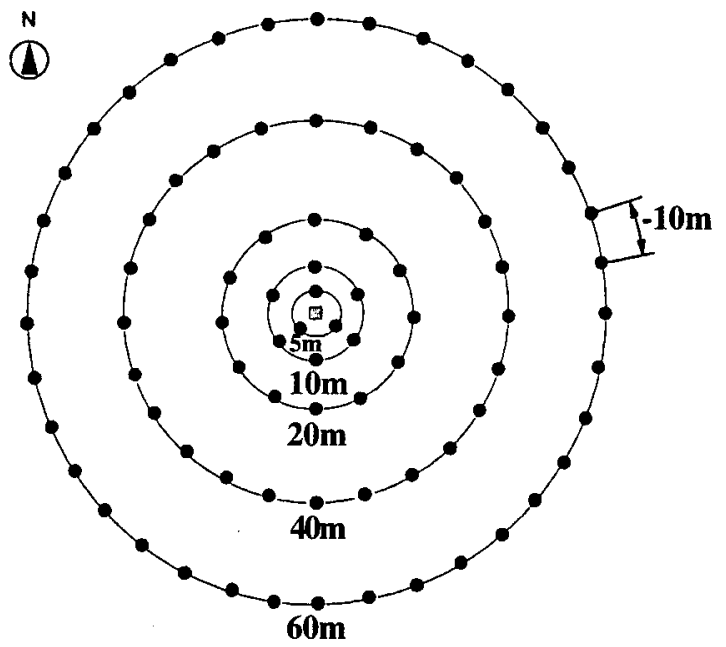

Fig. 1. Distribution of sentinel traps (sticky traps adjacent to caged greenbug-infested, potted sorghum plants) used to monitor L. testaceipes dispersal in a commercial grain sorghum field.

were folded and placed on stakes $(0.5 \mathrm{~m}$ tall $)$ at $10-\mathrm{m}$ intervals along concentric circles around the cage located at 5,10,20,40, and $60 \mathrm{~m}$ from the cage (Fig. 1). A caged plastic pot containing greenbug-infested sorghum seedlings was kept beside each trap to assure even infestation of the field and, therefore, attractiveness (Grasswitz and Paine 1992) because of very low levels of greenbugs or mummies in the field at the time of wasp release. Another sticky trap was placed in the center of the area covered by the field cage for $2 \mathrm{~d}$.

Sticky traps were replaced daily over a 5 -d period and held at $5^{\circ} \mathrm{C}$. Captured parasitoids were removed from traps, identified as Lysiphlebus spp. (Johnson et al. 1979), and transferred directly to clean $25-\mathrm{ml}$ bombs for $\mathrm{Rb}$ content analysis. The analytical procedures were as described above.

\section{Results}

Rb Detection in Greenbugs and Parasitoids. The relationship between the concentration of $\mathrm{RbCl}$ applied on plants and $\mathrm{Rb}$ concentration detected in both greenbugs and parasitoids indicated a significant quadratic trend (Fig. 2). It also is noticeable that the concentration of $\mathbf{R b}$ in parasitoids was slightly greater than in greenbugs at similar concentrations of applied $\mathrm{Rb}$.

Greenbugs and L. testaceipes reared on sorghum plants not treated with $\mathrm{RbCl}$ had $\mathrm{Rb}$ contents (ng/mg of dry body weight) of $27.56 \pm 5.87$ (mean $\pm \mathrm{SD}$ ), and $73.08 \pm 32.32$, respectively.

According to Stimmann (1974), an insect is considered to be labeled if trace element concentrations are $>3$ SDs above the mean background level. Thus, in this study, greenbugs and $L$. testaceipes were considered labeled if they exceeded 45.17 and $170.04 \mathrm{ng}$ of $\mathrm{Rb} / \mathrm{mg}$ of dry body weight, respec- 


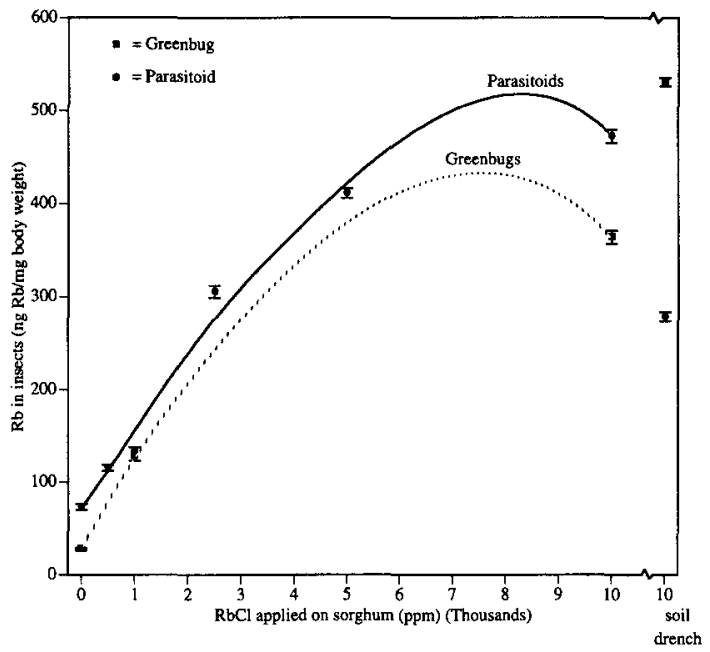

Fig. 2. Relationship between concentration of Rb (y) ( $\mathrm{ng} \mathrm{Rb} / \mathrm{mg}$ body weight [mean $\pm \mathrm{SE}$ ]) detected in greenbugs and parasitoids and concentration of $\mathrm{RbCl}$ (ppm) sprayed on sorghum plants $(x)$. Regression equations are as follows: greenbugs; $y=27.56( \pm 73.9)+0.11( \pm 0.12)$ $x-7.66 \times 10^{-6}\left( \pm 1.1 \times 10^{-6}\right) x^{2}\left(\mathbf{R}^{2}=0.64 ; \mathbf{F}=5.445 ; \mathrm{df}\right.$ $=2,6 ; P=0.045)$; parasitoid; $y=62.03( \pm 30.86)+0.10$ $( \pm 0.02) x-6.05 \times 10^{-6}\left( \pm 2.01 \times 10^{-6}\right) x^{2}\left(\mathrm{R}^{2}=0.75 ; \mathrm{F}\right.$ $=35.73 ; \mathrm{df}=2,24 ; P<0.001)$. The soil drench data points were not used in developing the regression equations.

tively. According to these criteria, foliar sprays of 2,500 ppm of $\mathrm{RbCl}$ should be the minimal level for labeling $L$. testaceipes, and greenbugs should be labeled using foliar sprays of at least $1,000 \mathrm{ppm}$ of $\mathrm{RbCl}$. Greenbugs and wasps caged on plants treated by a soil drench of $10,000 \mathrm{ppm} \mathrm{RbCl}$ also were labeled; they contained $530.77 \pm 60.60 \mathrm{ng}$ of $\mathrm{Rb} / \mathrm{mg}$ of dry body weight and $278.85 \pm 76.02$, respectively.

Rb Detection Throughout Parasitoid's Life Span. Analysis of variance indicated no significant variation $(F=0.02 ; \mathrm{df}=1,20 ; P=0.895)$ in the amount of $\mathbf{R b}$ during the parasitoid's life span (Fig. 3). However, there was a significant block effect $(F=$ $7.97 ; \mathrm{df}=1,20 ; P=0.011$ ). The block composed of pairs of parasitoids ( 1 male and 1 female) had declining Rb content with time. Also, although the insects used in this experiment belonged to the same laboratory colony used in the previous experiments, the amount of $\mathrm{Rb}$ in the parasitoids was much higher than detected during the 1st experiment (Fig. 2).

Rb Mobility in Sorghum Plants. Analysis of variance of the mean amount of $\mathrm{Rb}$ detected from both leaves shows that the treatment did not significantly increase $(F=5.73 ; \mathrm{df}=1,2 ; P=0.139)$ the $\mathrm{Rb}$ content in leaves. However, there was a significant interaction effect (rubidium $\times$ leaf) $(F=60.96$; $\mathrm{df}$ $=1,20 ; P<0.001$ ); the amount of $\mathrm{Rb}$ in $3 \mathrm{rd}$ and 6 th leaves were not significantly different $(F=0.00$; df $=1,20 ; P=0.999$ ) in the check but they were significantly different $(F=121.93 ; \mathrm{df}=1,20 ; P<$ 0.001 ) when $R b$ was sprayed. The younger leaf (leaf 6) contained less $\mathrm{Rb}$ compared with the older one

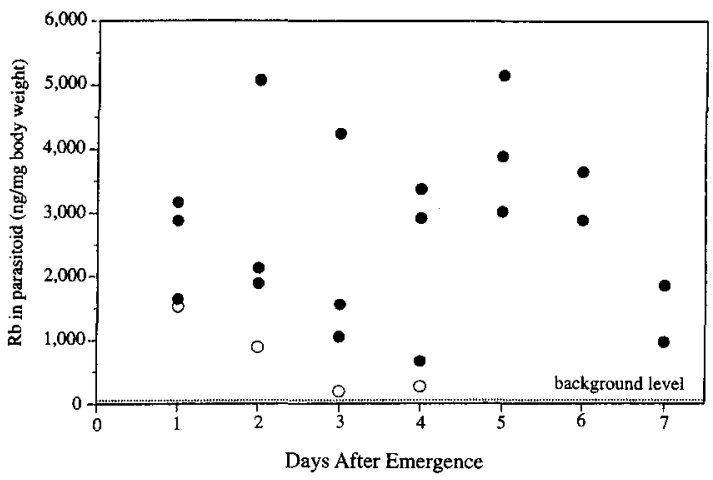

Fig. 3. Amount of rubidium (ng $\mathrm{Rb} / \mathrm{mg}$ body weight) in individual parasitoids throughout their life span compared with background level (52.60 $\mathrm{ng} \mathrm{Rb/mg} \mathrm{body}$ weight). Regression of rubidium content of parasitoids over time was not significant for either linear or quadratic components $(P>0.1) .0$, individuals held as pairs ( 1 male and 1 female); $\bullet$ wasps maintained individually.

(leaf 3) (Table 1). However, despite this, greenbug rubidium content was significantly influenced only by the rubidium treatment $(F=6.28 ; \mathrm{df}=1,17 ; P$ $=0.023$ ) , and greenbugs were labeled regardless of whether they fed on leaf 3 (previously sprayed with rubidium) or leaf 6 (emerged after rubididum treatment) (Table 1).

Release-Recapture Study. In total, 19 parasitoids were caught by the sticky traps during the study period. Five parasitoids were caught at the $0-\mathrm{m}$ location (cage area) and 14 were caught by the sticky traps placed around the release site. However, 1 parasitoid could not be retrieved from the sticky trap and only 18 insects were analyzed for $\mathrm{Rb}$ content. All trapped parasitoids contained high amounts of $\mathrm{Rb}$ (980.76-1519.23 $\mathrm{ng} \mathrm{Rb} / \mathrm{mg}$ of body weight) when compared with the background level detected in nonlabeled insects. Therefore, we assume that all 18 parasitoids trapped and analyzed were labeled by $\mathrm{RbCl}$ sprayed on plants at the release site. They were able to spread several meters on the first $2 \mathrm{~d}$ after release (Fig. 4), and even the most distant traps caught several individuals. The wind direction and speed might have influenced the dispersal of the parasitoid because, overall, there was a relationship between wind direction and parasitoid flight directions; most movement appeared to be downwind (Fernandes 1995). Natural infesta-

Table 1. Mean ( \pm SE) amount (ng/mg of dry matter) of Rb detected in greenbugs and seedling sorghum leaves

\begin{tabular}{cccccc}
\hline \hline \multirow{2}{*}{$\begin{array}{c}\text { Sorghum } \\
\text { leaf }\end{array}$} & \multicolumn{2}{c}{ Amt of Rb in leaf } & & \multicolumn{2}{c}{ Amt of Rb in greenbug } \\
\cline { 2 - 3 } \cline { 5 - 6 } & Untreated & RbCl-treated & & Untreated & RbCl-treated \\
\hline 3rd & 74.31 & $7,850.97$ & 6.09 & 80.38 \\
& $( \pm 18.73)$ & $( \pm 796.16)$ & & $( \pm 0.77)$ & $( \pm 36.27)$ \\
6th & 74.22 & $1,576.00$ & & 11.86 & 25.96 \\
& $( \pm 22.27)$ & $( \pm 417.27)$ & & $( \pm 3.89)$ & $( \pm 4.34)$ \\
\hline
\end{tabular}



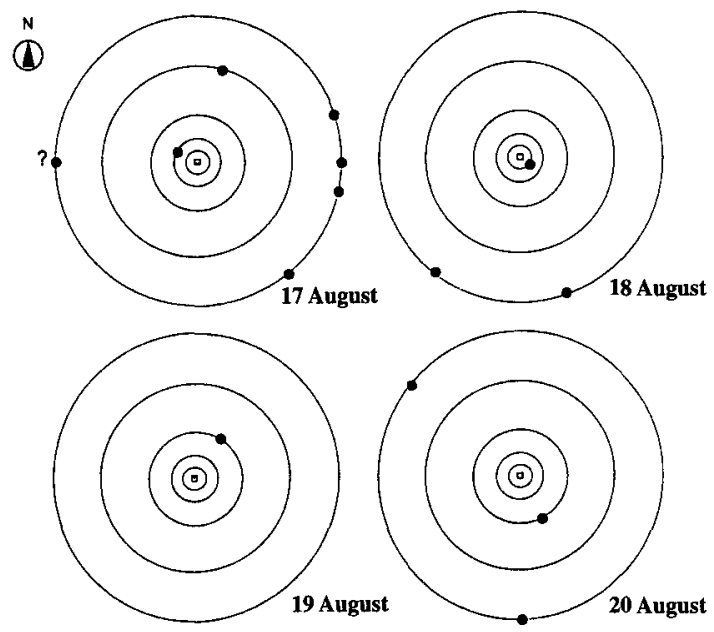

Fig. 4. Location of parasitoids captured by sticky traps in release-recapture study using $\mathrm{Rb}$-labeled wasps. Circles represent $5,10,20,40$, and $60 \mathrm{~m}$ from central release site (see Fig. 1). Each solid circle represents 1 labeled parasitoid caught, based on later analysis of $\mathrm{Rb}$ content. ?, location of a trapped parasitoid whose $\mathrm{Rb}$ content was not analyzed.

tions of aphids and parasitoids were scarce in the field during the study.

\section{Discussion}

This study demonstrates that both $L$. testaceipes and greenbugs can be labeled with $\mathrm{Rb}$ when sorghum plants were sprayed to runoff with concentrations of $\mathrm{RbCl}>2,500 \mathrm{ppm}$. Parasitoid labeling with $\mathrm{Rb}$ was also accomplished by Corbett et al (1996), Jackson et al. (1988), Jackson and Debolt (1990), and Hopper (1991) with other hymenopteran species, whereas Guillebeau et al. (1993) labeled another aphid species.

Rubidium content in new, unsprayed leaves of plants sprayed $32 \mathrm{~d}$ earlier was higher than in leaves from untreated plants. This shows that $\mathbf{R b}$ is mobile within the plant. Greenbugs feeding on the new, unsprayed leaves obtained sufficient $\mathrm{Rb}$ to become labeled (Table 1). Therefore, greenbugs could be labeled up to $4 \mathrm{wk}$ after spraying the plants. Although, parasitized greenbugs were not tested during the $\mathbf{R b}$ mobility assay, the 1st experiment showed that the Rb content of both greenbugs and parasitoids were very similar (Fig. 3). Therefore, we speculate that parasitoids would be labeled if they also developed within this period. As Levi (1968, 1970 ) has shown, $\mathrm{Rb}$ can replace $\mathrm{K}$ and is also highly mobile in plants. Levi studied the mobility of $\mathrm{Rb}$ and observed a rapid translocation to new leaves within a few hours following treatment. Therefore, this should result in labeling, even though insects may appear on a plant several days after treatment.
This is the 1st report of relatively long-distance dispersal by $L$. testaceipes. This parasitoid moved at least $60 \mathrm{~m}$ in $1 \mathrm{~d}$, which is much farther than previously reported (Starks et al. 1973) These results indicate that $\mathrm{Rb}$ can be used as a physiological marker in release-recapture studies of $L$. testaceipes under field conditions. Additional studies of L. testaceipes dispersal are needed to define its dispersal ability better. This information would be useful in developing strategies for augmentative releases of $L$. testaceipes as a biological control of greenbugs.

The use of sentinel traps (association of greenbug-infested plants and sticky traps) is feasible for L. testaceipes and probably other parasitoid dispersal studies. However, they may not be needed if studies are done in a field with abundant hosts. Lysiphlebus testaceipes remained labeled for $7 \mathrm{~d}$ after emergence, although the variability of the data was very high (Fig. 3). The amount of $\mathbf{R b}$ observed in these insects was $\approx 10$ times that in the previous experiment (Fig. 2). It is possible that the insects brought to the laboratory may exhibit different uptake and excretion rates. It also is possible that pairs of parasitoids or even groups may have trace element levels decreased at a much higher rate because of greater possibility of mating and oviposition. Jackson et al. (1988) used Rb to label Anaphes ovijentatus (Crosby \& Leonard), an egg parasitoid of Lygus spp. The authors reported that the parasitoids fed on diets containing 500 or $1,000 \mathrm{ppm}$ of $\mathrm{RbCl}$ were labeled up to $4 \mathrm{~d}$ after emergence. Corbett et al. (1996) reported minimal decay of $\mathrm{Rb}$ levels in labeled Anagrus epos Girault adults, but this mymarid did not live $>72 \mathrm{~h}$ after adult emergence.

Although Akey and Burns (1991) did not report ICP spectroscopy to be among the best analytical procedures, in our study it was able to detect $\mathrm{Rb}$ with sufficient sensitivity to distinguish between natural and artificial levels of $\mathbf{R b}$ in individual greenbugs and wasps. However, this technique is expensive. Each run (1 insect) cost approximately US $\$ 15$. For larger numbers of insects, as would be needed for dispersal studies, atomic absorption spectrophotometry may be preferred because of cost considerations.

\section{Acknowledgments}

We thank Linda J. Young (Department of Biometry, University of Nebraska-Lincoln) for suggestions concerning statistical analysis of data, and Blair Siegfried and Steve Danielson (Department of Entomology, University of Nebraska-Lincoln) for reviewing drafts of this manuscript. Odair Fernandes was supported by an assistantship from Fundação de Amparo à Pesquisa do Estado de São Paulo (FAPESP). This research was supported by the University of Nebraska Agricultural Experiment Station, Project Nos. 48-022 and 17-057. This paper is Journal Series No. 11649 of the Agricultural Research Division, University of Nebraska and Contribution No. 930 of the Department of Entomology. 


\section{References Cited}

Akey, D. H. 1991. A review of marking techniques in arthropods and an introduction to elemental marking. Southwest. Entomol. (suppl.) 14: 1-8.

Akey, D. H., and D. W. Burns. 1991. Analytical consideration and methodologies for elemental determination in biological samples. Southwest. Entomol. (suppl.) 14: 25-36

Berry, W. L., M. W. Stimmann, and W. W. Wolf. 1972. Marking of native phytophagous insects with rubidium: a proposed technique. Ann. Entomol. Soc. Am. 65: $236-238$.

Corbett, A., B. C. Murphy, J. A. Rosenheim, and P. Bruins. 1996. Labelling an egg parasitoid, Anagrus epos (Hymenoptera: Mymaridae), with rubidium within an overwintering refuge. Environ. Entomol. 25: 29-38.

Fernandes, Odair Aparecido. 1995. Population dynamics and spatial distribution of Lysiphlebus testaceipes (Cresson) (Hymenoptera: Braconidae) and its host, the greenbug, Schizaphis graminum Rondani (Homoptera: Aphididae): studies for the development of an augmentation program. $\mathrm{Ph}$. $\mathrm{D}$. dissertation, University of Nebraska-Lincoln.

Fleischer, S. J., M. J. Gaylor, N. V. Hue, and L. C. Graham. 1986. Uptake and elimination of rubidium, a physiological marker in adult Lygus lineolaris (Hemiptera: Miridae). Ann. Entomol. Soc. Am. 79: 19-25.

Frazer, B. D., and D. A. Raworth. 1974. Marking aphids with rubidium. Can. J. Zool. 52: 1135-1136.

Graham, H. M., and D. A. Wolfenbarger. 1977. Tobacco budworm: labeling with rubidium in the laboratory. J. Econ. Entomol. 70: 800-802.

Graham, H. M., D. A. Wolfenbarger, and J. B. Nosky. 1978. Labeling plants and their insect fauna with rubidium. Environ. Entomol. 7: 379-383.

Grasswitz, T. R., and T. D. Paine. 1992, Kairomonal effect of an aphid cornicle secretion on Lysiphlebus testaceipes (Cresson) (Hymenoptera: Aphididae). J. Insect Behav. 5: 447-457.

Guillebeau, L. P., J. N. All, F. W. Nutter, Jr., and C. Kuhn. 1993. Comparison of foliar and soil-drench application of aqueous rubidium chloride solutions to plants for marking feeding aphids (Homoptera: Aphidae). J. Entomol. Sci. 28: 370-375.

Hayes, J. L. 1991. Elemental marking of arthropod pests in agricultural systems: single and multigeneration marking. Southwest. Entomol. (suppl.) 14: 37-47.

Hopper, K. R. 1991. Ecological applications of elemental labeling: analysis of dispersal, density, mortality, and feeding. Southwest. Entomol. (suppl.) 14: 71-83.

Jackson, C. G. 1991. Elemental markers for entomophagous insects. Southwest. Entomol. (suppl.) 14: $65-69$.
Jackson, C. G., and J. W. Debolt. 1990. Labeling of Leiophron uniformis, a parasitoid of Lygus spp., with rubidium. Southwest. Entomol. 15: 239-243.

Jackson, C. G., A. C. Cohen, and C. I. Verdugo. 1988. Labeling Anaphes ovijentatus (Hymenoptera: Mymaridae), an egg parasite of Lygus spp. (Hemiptera: Miridae), with rubidium. Ann. Entomol. Soc. Am. 81: $919-$ 922 .

Johnson, J. W., R. D. Eikenbary, and D. Holbert. 1979. Parasites of the greenbug and other graminaceous aphids: identity based on larval meconia and features of the empty aphid mummy. Ann. Entomol. Soc. Am. 72: $759-766$.

Levi, E. 1968. The distribution of mineral elements following leaf and root uptake. Physiol. Plant. 21: 213-226. 1970. Penetration, retention and transport of foliar applied single salts of Na, K., Rb and Cs. Physiol. Plant. 23: 811-819.

Morgan, J., G. Wilde, and D. Johnson. 1980. Greenbug resistance in commercial hybrids in the seedling stage. J. Econ. Entomol. 73: 510-514.

SAS Institute. 1990. SAS/STAT user's guide, vol. 1. Cary, NC.

Southwood, T.R.E. 1978. Ecological studies with particular reference to the study of insect populations, 2nd ed. Chapman \& Hall, London.

Starks, K. J., R. L. Burton, E. A. Wood, Jr., G. L. Teetes, J. W. Johnson, W. J. Lewis, A. N. Sparks, R. L. Jones, D. E. Weibel, T. A. Archer, and R. D. Eikenbary. 1973. Alternate methods for greenbug control on sorghum. Unpublished Report, Department of Entomology, Oklahoma State University.

Stimmann, M. W. 1974. Marking insects with rubidium: imported cabbageworm marked in the field. Environ. Entomol. 3: 327-328.

1991. A personal history of the development of the rubidium marking technique. Southwest. Entomol. (suppl.) 14: 9-13.

Stimmann, M. W., W. W. Wolf, and W. L. Berry. 1973. Cabbage looper biological effects of rubidium in the larval diet. J. Econ. Entomol. 66: 324-326.

Vanderlip, R. L. 1972. How a sorghum plant develops. Kans. State Univ. Coop. Ext. Serv., Manhattan.

Van Steenwyk, R. A. 1991. The uses of elemental marking for insect dispersal and mating competitiveness studies: from the laboratory to the field. Southwest. Entomol. (suppl.) 14: 15-23.

Van Steenwyk, R. A., G. R. Ballmer, A. L. Page, and H. T. Reynolds. 1978. Marking pink bollworm with rubidium. Ann. Entomol. Soc. Am. 71: 81-84.

Received for publication 30 August 1996; accepted 6 June 1997. 